\title{
The Antiproliferative Activity of Saponin-Enriched Fraction from Bupleurum Kaoi Is through Fas-Dependent Apoptotic Pathway in Human Non-small Cell Lung Cancer A549 Cells
}

\author{
Ya-Ling Hsu, ${ }^{a}$ Po-Lin Kuo, ${ }^{b}$ Ting-Chun Weng, ${ }^{a}$ Ming-Hong Yen, ${ }^{a}$ Lien-Chai Chiang, ${ }^{c}$ and \\ Chun-Ching Lin*,a \\ ${ }^{a}$ Graduate Institute of Natural Products, College of Pharmacy, Kaohsiung Medical University; No. 100, Shin-Chuan 1'st \\ Road, Kaohsiung 807, Taiwan: ${ }^{b}$ Department of Pharmacy, Chia-Nan University of Pharmacy and Science; 60 Section 1, \\ Erh-Jen Road, Tainan 717, Taiwan: and ${ }^{c}$ Graduate Institute of Medicine, College of Medicine, Kaohsiung Medical \\ University; No. 100, Shin-Chuan 1'st Road, Kaohsiung 807, Taiwan. \\ Received December 31, 2003; accepted February 25, 2004
}

Bupleuri Radix (Chai-hu in Chinese and Saiko in Japanese) is one of the most important traditional Chinese crude drugs for treating hepatitis malaria and intermittent fever. B. kaoi is one of the Bupleurum spp. families locally found in Taiwan. The effects of saponin-enriched fraction (SEF) from Bupleurum Kaoi in human non-small cell lung cancer A549 cells were investigated in this study. An enhancement in Fas and its two forms of ligands, membrane-bound Fas ligand (mFasL) and soluble Fas ligand (sFasL), was responsible for the apoptotic effect induced by SEF. Taken together, our study suggests that the activity of the Fas/Fas ligand apoptotic system may participate in the antiproliferative activity of SEF in A549 cells.

Key words saponin-enriched fraction; Bupleurum Kaoi; Fas; Fas ligand; apoptosis

Lung cancer is the leading cause of cancer death in the world, and non-small cell lung carcinoma (NSCLC) accounts for approximately $75-85 \%$ of these cancers. Non-small cell lung cancers commonly develop resistance to radiation and chemotherapy, and they often present at stages beyond surgical remedy. Since current treatment modalities are inadequate, novel therapies are necessary to reduce the effects of the increasing incidence in pulmonary neoplasm. ${ }^{1,2)}$

Bupleuri Radix (Chai-hu in Chinese and Saiko in Japanese) is one of the most important traditional Chinese crude drugs for treating hepatitis malaria and intermittent fever. It has been used in many Chinese medicine prescriptions to treat deafness, dizziness, irregular menstruation, lung disease, jaundice, liver disease and amenorrhea. Among them, B. kaoi is one of the Bupleurum spp. families locally found in Taiwan. ${ }^{3)}$ Previous studies have shown that Bupleuri Radix possesses a wide range of immunopharmacologic functions, such as anti-inflammatory, mitogen-induced lymphocyte transformation, or antiviral activities. ${ }^{4-6)}$ A recent study reported that the acetone extract of Bupleurum scorzonerifolium could inhibit proliferation of A549 human lung cancer cells by inducing apoptosis and suppressing telomerase activity. ${ }^{1)}$

Apoptosis has been characterized as a fundamental cellular activity to maintain the physiological balance of the organism. It is also involved in immune defense machinery and plays a necessary role as a protective mechanism against carcinogenesis by eliminating damaged cells or abnormal excess cells proliferated owing to various chemical agents' induction. ${ }^{7)}$ In this study, we determined the antiproliferative activity of SEF, and examined its effect on apoptosis in the human lung cancer cell line, A549. Furthermore, to establish the anticancer mechanism of SEF, we assayed the levels of Fas/ APO-1 receptor and Fas ligand which are strongly associated with the signal transduction pathway of apoptosis and affect the chemosensitivity of tumor cells to anticancer agents.

\section{MATERIALS AND METHODS}

Materials Fetal bovine serum (FBS), penicillin G, streptomycin, and amphotericin B were obtained from GIBCO BRL (Gaithersburg, MD, U.S.A.). Dimethyl sulfoxide (DMSO) and RPMI-1640 were purchased from Sigma Chemical (St. Louis, MO, U.S.A.). Sodium 3'-[1-(phenylaminocarbonyl)-3,4-tetrazolium]-bis(4-methoxy-6-nitro) benzenesulfoic acid hydrate (XTT) kit was obtained from Roche Diagnostics GmbH (Germany). Nucleosome ELISA, Fas Ligand, and Fas/APO-1 ELISA kits were purchased from Calbiochem (Cambridge, MA, U.S.A.).

Preparation of B. kaoi Extracts Saponin-enriched fraction (SEF) was extracted from the roots of B. kaoi using the methods of Lin $e a^{a l}{ }^{3)}$ SEF was dissolved in dimethyl sulfoxide (DMSO) and stored at $-20^{\circ} \mathrm{C}$. For all experiments, final concentrations of the tested compound were prepared by diluting the stock with RPMI-1640. Control cultures received the carrier solvent $(0.1 \%$ DMSO).

Cell Culture A549 (American Type Culture Collection [ATCC] CCL185) was maintained in monolayer culture at $37{ }^{\circ} \mathrm{C}$ and $5 \% \mathrm{CO}_{2}$ in RPMI- 1640 supplemented with $10 \%$ FBS, $10 \mathrm{U} / \mathrm{ml}$ of penicillin, $10 \mu \mathrm{g} / \mathrm{ml}$ of streptomycin, and $0.25 \mu \mathrm{g} / \mathrm{ml}$ of amphotericin B.

Cell Proliferation Assay Inhibition of cell proliferation by SEF was measured by XTT assay. Briefly, cells were plated in 96 -well culture plates $\left(1 \times 10^{4}\right.$ cells/well $)$. After $24 \mathrm{~h}$ incubation, the cells were treated with $\operatorname{SEF}(0,20,100,200$, $400 \mu \mathrm{g} / \mathrm{ml}$ ) for $12,24,48$, and $72 \mathrm{~h}$. Fifty microliters of XTT test solution, which was prepared by mixing $5 \mathrm{ml}$ of XTT-labeling reagent with $100 \mu \mathrm{l}$ of electron coupling reagent, was then added to each well. After $6 \mathrm{~h}$ of incubation, the absorbance was measured on an ELISA reader (Multiskan EX, Labsystems) at a test wavelength of $492 \mathrm{~nm}$ and a reference wavelength of $690 \mathrm{~nm}$.

Measurement of Apoptosis by ELISA The induction of apoptosis by SEF was assayed using the Nucleosome ELISA 
kit. This kit uses a photometric enzyme immunoassay that quantitatively determines the formation of cytoplasmic histone-associated DNA fragments (mono and oligonucleosomes) after apoptotic cell death. For determination of apoptosis by ELISA, the A549 cells were treated with SEF at 0, 100 , and $200 \mu \mathrm{g} / \mathrm{ml}$ for $6,12,24$, and $48 \mathrm{~h}$ in a 96 well plate. The induction of apoptosis was evaluated by assessing the enrichment of nucleosome in cytoplasm, and determined exactly as described in the manufacturer's protocol. ${ }^{8,9)}$

Assaying the Levels of Fas and Fas Ligand (mFasL and sFasL) Fas ligand and Fas ELISA kits were used to detect Fas ligand and Fas receptor. Briefly, A549 cells were treated with 0,100 and $200 \mu \mathrm{g} / \mathrm{ml}$ of SEF for $6,12,24$, and $48 \mathrm{~h}$. The samples of cell lysate were placed in 96 well $\left(1 \times 10^{6}\right.$ cells/well) microtiter plates coated with monoclonal detecting antibodies, and were incubated for $1 \mathrm{~h}$ (Fas) or $3 \mathrm{~h}$ (FasL) at room temperature. After removing the unbound material by washing with PBS, horseradish peroxidase conjugated streptavidin was added to bind to the antibodies. Horseradish peroxidase catalyzed the conversion of a chromogenic substrate (tetramethylbenzidine) to a colored solution with color intensity proportional to the amount of protein present in the sample. The absorbance of each well was measured at 450 nm. Concentrations of Fas and FasL were determined by interpolating from standard curves obtained with known concentrations of standard proteins. ${ }^{10,11)}$

Assay for Caspase-8 Activity The assay is based on the ability of the active enzyme to cleave the chromophore from the enzyme substrate, Ac-IETD-pNA. The cell lysates were incubated with peptide substrate in assay buffer $(100 \mathrm{~mm}$ $\mathrm{NaCl}, 50 \mathrm{~mm}$ HEPES, $10 \mathrm{~mm}$ dithiothreitol, 1 mм EDTA, 10\% glycerol, $0.1 \%$ CHAPS, $\mathrm{pH} 7.4$ ) for $3 \mathrm{~h}$ at $37^{\circ} \mathrm{C}$. The release of $p$-nitroaniline was monitored at $405 \mathrm{~nm}$. Results are represented as the percent change of the activity compared to the untreated control. ${ }^{12)}$

Statistical Analysis Data were expressed as means \pm S.D. Statistical comparisons of the results were made using analysis of variance (ANOVA). Significant differences $(p<$ $0.05)$ between the means of control and SEF-treated cells were analyzed by Dunnett's test. For the effect of inhibitors (ZB4, Z-IETD-FMK), this type of statistical analysis was performed using ANOVA, followed by Fisher's PLSD test.

\section{RESULTS}

We first tested the antiproliferative effect of SEF in the lung cancer cell line, A549. As shown in Fig. 1, this proliferation inhibitory effect was observed to be dose-dependent. Its $\mathrm{IC}_{50}$ value was $196 \mu \mathrm{g} / \mathrm{ml}$.

Figure 2 shows the time course of DNA fragmentation in continuous treatment with 100 and $200 \mu \mathrm{g} / \mathrm{ml}$ of SEF. DNA fragmentation of A549 was found at $12 \mathrm{~h}$ and maximized at $48 \mathrm{~h}$ after addition of SEF. In contrast to the control, when cells were treated with SEF, the number of cells undergoing apoptosis increased from about 3 fold to 7.3 fold at 100 and $200 \mu \mathrm{g} / \mathrm{ml}$ of SEF, respectively, at $48 \mathrm{~h}$.

The expression of Fas was detected in A549 cells at $6 \mathrm{~h}$ after SEF treatment. Maximum Fas was detected at $24 \mathrm{~h}$ (Fig. 3A). Results on Fas ligand assay indicated that FasL, mFasL, and sFasL increased in a dose-dependent manner (Figs. 3B, C). The accumulation of mFasL was observed at $6 \mathrm{~h}$ after

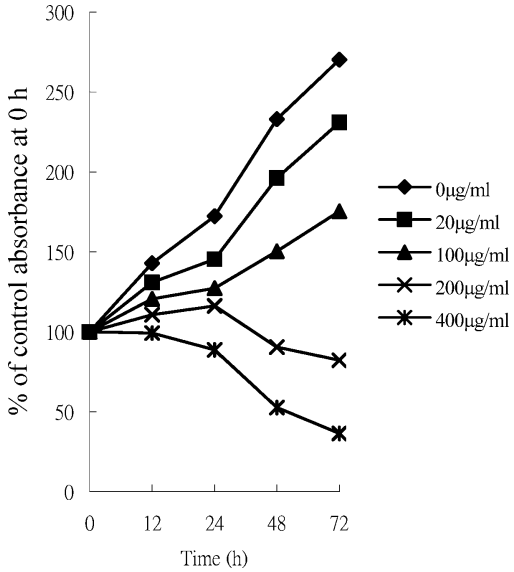

Fig. 1. The Antiproliferative Effect of SEF in A549 Cells

Adherent cells plated in 96 -well plates $\left(10^{4}\right.$ cells/well $)$ were incubated with different concentrations of SEF at various time intervals. Cell proliferation was determined by XTT assay. Results are expressed as the percent of the cell proliferation of control at $0 \mathrm{~h}$. Standard deviations were less than $10 \%$.

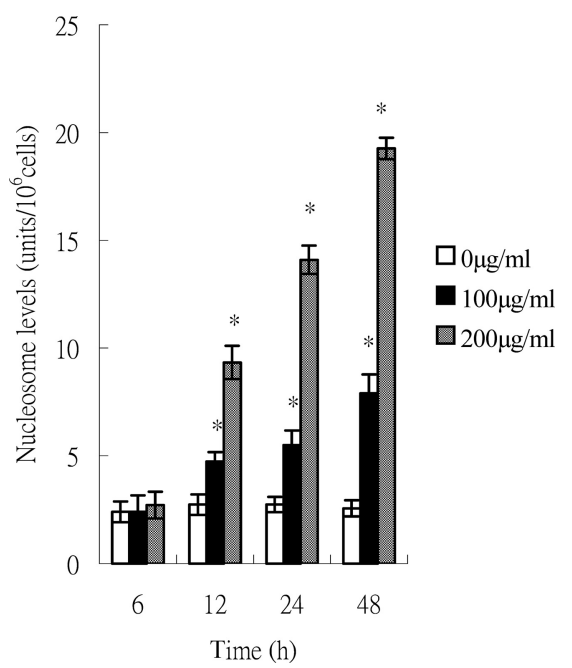

Fig. 2. Induction of Apoptosis in A549 Cells by SEF

A549 cells were cultured with 0,100 and $200 \mu \mathrm{g} / \mathrm{ml}$ of SEF for $6,12,24$ and $48 \mathrm{~h}$. Cells were harvested and lysed with lysis buffer. Cell lysates containing cytoplasmic oligonucleosomes of apoptotic cells were analyzed by means of Nucleosome ELISA. Each value is the mean \pm S.D. of three determinations. The asterisk indicates a significant difference between control and SEF-treated cells as analyzed by Dunnett's test $(p<0.05)$.

SEF treatment, and progressively increased up to $24 \mathrm{~h}$ (Fig. 3B). A similar result was observed for sFasL (Fig. 3C). However, the amount of mFasL was more than sFasL at all time points.

When A549 cells were pre-treated with an antagonistic anti-Fas antibody, ZB4, the antiproliferative and proapoptotic effects of SEF were effectively inhibited. At $200 \mu \mathrm{g} / \mathrm{ml}$ of $\mathrm{SEF}$, the cell proliferative inhibition decreased from 61.2 to $21.22 \%$ (Fig. 4A). Compared to the control, the oligonucleosome DNA fragmentation of apoptosis induced by $200 \mu \mathrm{g} / \mathrm{ml}$ of SEF decreased from about 7.5 fold to 2.4 fold at $48 \mathrm{~h}$ in ZB4 pretreated A549 cells (Fig. 4B).

We next measured the downstream caspase of the Fas/FasL system. The results showed that caspase- 8 activity increased at $12 \mathrm{~h}$, and reached maximum induction at $48 \mathrm{~h}$ in $200 \mu \mathrm{g} / \mathrm{ml}$ SEF treated A549 cells (Fig. 5A). Furthermore, we found that the antiproliferative activity and induction of apoptosis 

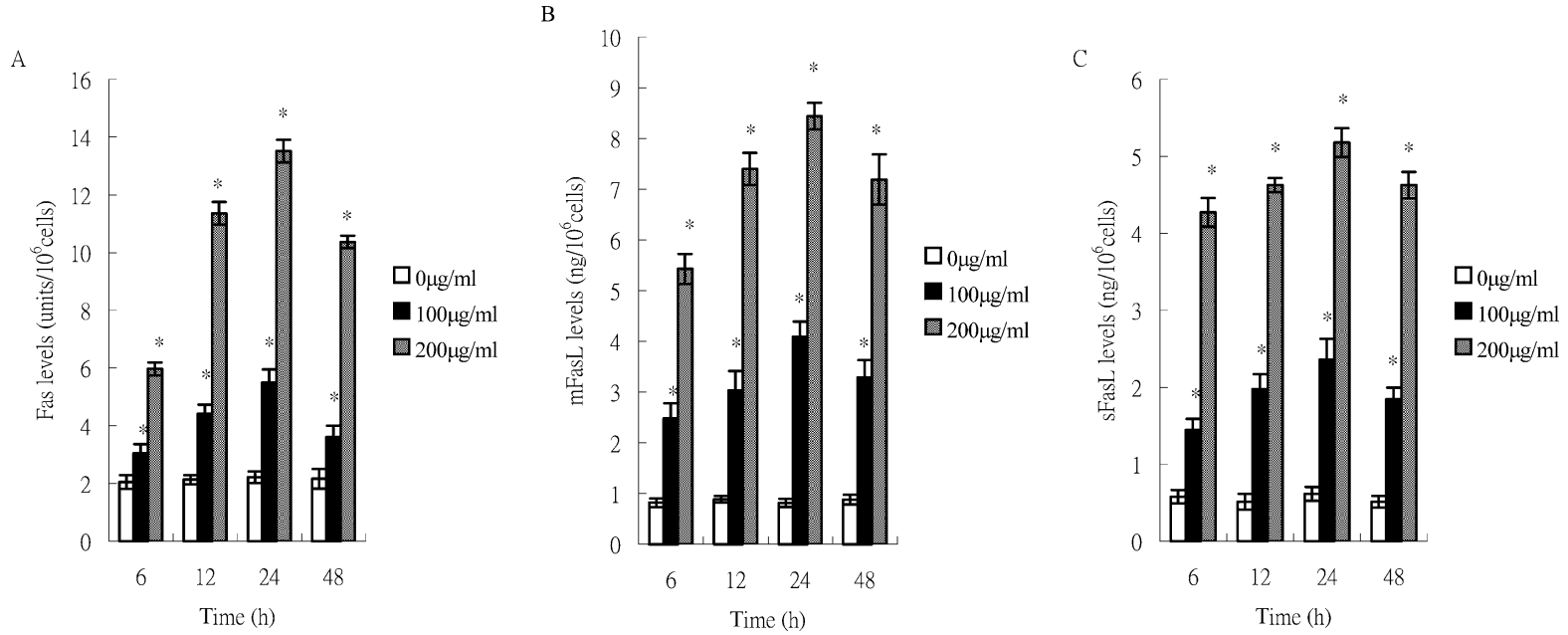

Fig. 3. Fas/FasL Apoptotic System was Involved in Crude Saponin-Mediated Apoptosis

A549 cells were incubated with 0,100 and $200 \mu \mathrm{g} / \mathrm{ml}$ of SEF for $6,12,24$ and $48 \mathrm{~h}$. (A) The level of Fas receptor in A549 cells. (B) The amount of mFasL in A549 cells. (C) The amount of sFasL in A549 cells. Each value is the mean \pm S.D. of three determinations. The asterisk indicates a significant difference between control and SEF-treated cells as analyzed by Dunnett's test $(p<0.05)$.
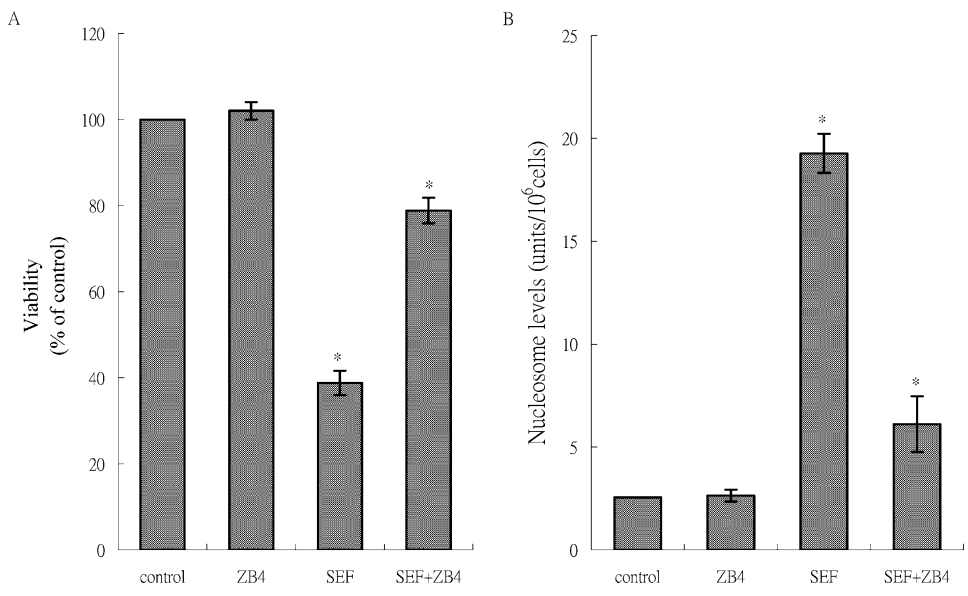

Fig. 4. Effect of Antagonistic Anti-Fas Antibody (ZB4) on SEF in A549 Cells

(A) The antiproliferative and (B) proapoptotic effect of SEF was decreased by Fas antagonist ZB4. For blocking experiments, cells were preincubated with $250 \mathrm{ng} / \mathrm{ml} \mathrm{ZB} 4$ for $1 \mathrm{~h}$ and then treated with $200 \mu \mathrm{g} / \mathrm{ml}$ of SEF for $48 \mathrm{~h}$. Cell viability and apoptosis induction was examined by XTT and Nucleosome ELISA kit. The data shown are the mean \pm S.D. of three independent experiments. The asterisk indicates a significant difference between control and SEF-treated cells as analyzed by Fisher's PLSD test $(p<0.05)$.
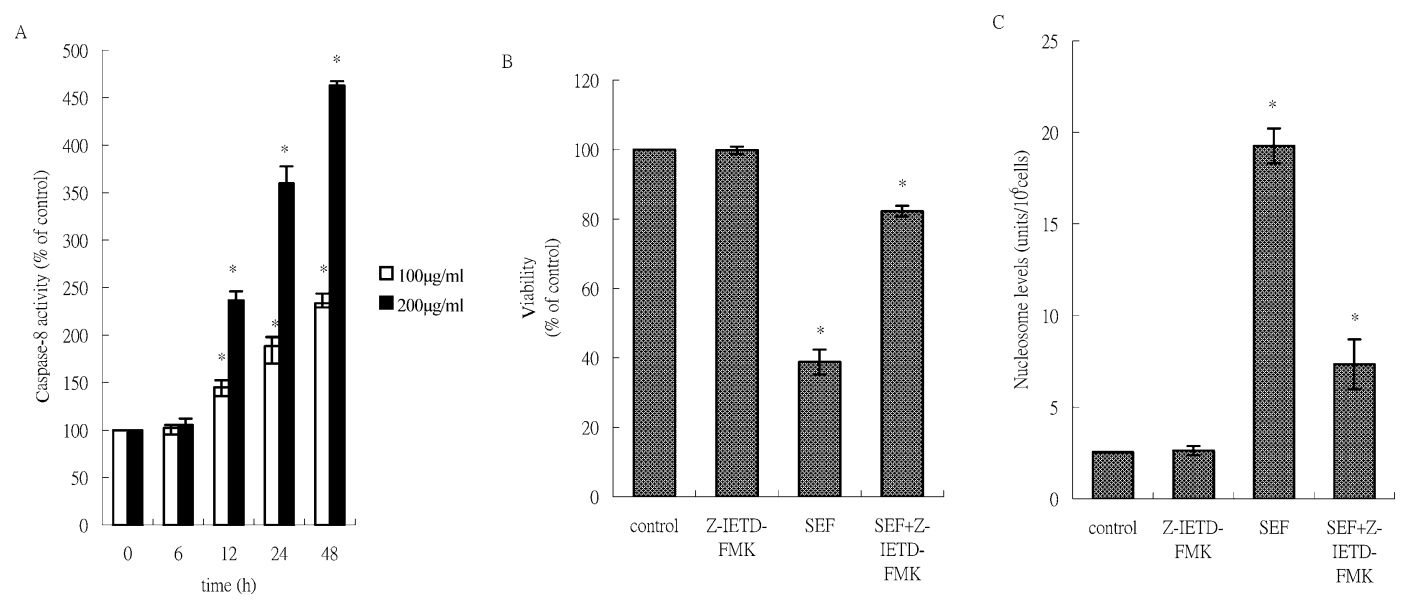

Fig. 5. (A) The Activation of Caspase-8 in A549 Cells by SEF; (B) Effect of Caspase-8 Inhibitor on SEF-Mediated Antiproliferation; (C) Effect of Caspase-8 Inhibitor on SEF-Induced Apoptosis

A549 cells were incubated with various concentrations of SEF for the indicated times. For blocking experiments, cells were preincubated with Z-IETD-FMK ( $10 \mu \mathrm{M}$ ) for $1 \mathrm{~h}$ before the addition of $200 \mu \mathrm{g} / \mathrm{ml} \mathrm{SEF}$. After $48 \mathrm{~h}$ treatment, the cell viability and induction of apoptosis was measured by XTT and Nucleosome ELISA kit. Each value is the mean \pm S.D. of three determinations. The asterisk indicates a significant difference between control and SEF-treated cells as analyzed by Fisher's PLSD test $(p<0.05)$. 
by SEF were significantly decreased in the presence of inhibitor of caspase-8 (Z-IETD-FMK) (Figs. 5B, C).

\section{DISCUSSION}

B. kaoi is one of the Bupleurum spp. families locally found in Taiwan. It has been indicated that that the roots, rhizomes and aerial parts (leaves and stem) have greater quantities of saikosaponins than other species of Bupleurum spp. ${ }^{13)}$ A number of studies have indicated that the activated saponins of Bupleurum spp. families, including saikosaponin A, B1 and $\mathrm{D}$, exhibited a significant cell proliferation effect against various cancer lines. ${ }^{14-18)}$ Saikosaponin A has been reported to inhibit cell growth in Hep G2, MCF-7, MDA-MB-231, and $\mathrm{HuH}-7$ cancer cell lines. ${ }^{14-16)} \mathrm{Bu}$ et al. reported that Saikosaponin D treatment resulted in an inhibition of proliferation and induction of apoptosis through up-regulation of GR mRNA expression in HL-60 cells. ${ }^{17)}$ Study has also shown that Saikosaponin B2 blocks the cell cycle progression at G1 phase and induces apoptosis in rat B16 melanoma cells. ${ }^{18)}$ In our work, we demonstrated that the saponin-enriched fraction (SEF) of B. kaoi inhibited the cell proliferation in $\mathrm{A} 549$ by inducing apoptotic cell death.

Apoptosis induced by chemotherapy seems to involve the upregulation of Fas ligand and induced cell killing controlled by Fas/APO- $1 .{ }^{19,20)}$ Binding Fas ligand to Fas receptor leads to receptor trimerization and recruitment of adaptor proteins (FADD) and procaspase- 8 to form a death-inducing signaling complex (DISC). Next, procaspase-8 is activated prototypically and cleaves to various substrates, including procaspase3 , which results in its activation and the completion of cell death. ${ }^{7,21)}$ FasL is a TNF related type II membrane protein. Cleavage of membrane-bound Fas ligand (mFasL) by a metalloprotease-like enzyme results in the formation of soluble Fas ligand (sFasL) ${ }^{22)}$ Recent study has indicated that Fas/ APO-1 is expressed in human airway epithelial cells and has a critical role in the pathophysiology of various pulmonary disorders. ${ }^{23)}$ Upregulation of Fas/APO-1 expression has been demonstrated to induce apoptosis in hydrogen peroxidetreated A549 cells. Serrao et al. have reported that neutrophils induce apoptosis of lung epithelial cells via release of soluble FasL. ${ }^{24)}$ Our study indicated that Fas ligands, mFasL and sFasL, increased in SEF-treated A549 cells. Moreover, the level of Fas/APO-1 and the activity of caspase8 were simultaneously enhanced in FasL-upregulating A549 cells. Furthermore, when the Fas/Fas ligand system was blocked by ZB4, a decrease in cell growth inhibition and proapoptotic effect of SEF was noted. Similarly, cell growth inhibition and apoptotic induction of SEF decreased in A549 cells with caspase- 8 inhibitor treatment. Thus, our results demonstrated that the Fas/FasL system plays an important role in SEF-mediated A549 cellular apoptosis.

In summary, our study demonstrates that the antiproliferative activity of SEF from Bupleurum Kaoi is through the Fasdependent apoptotic pathway in human non-small cell lung cancer A549 cells. We demonstrated that SEF appears to be a promising chemopreventive agent for treating lung cancer.

\section{REFERENCES}

1) Cheng Y. L., Chang W. L., Lee S. C., Liu Y. G., Lin H. C., Chen C. J., Yen C. Y., Yu D. S., Lin S. Z., Harn H. J., Life Sci., 73, 2383-2394 (2003).

2) Kim P. K., Park S. Y., Koty P. P., Hua Y., Luketich J. D., Billiar T. R., J. Thorac. Cardiovasc. Surg., 125, 1336-1342 (2003).

3) Lin C. C., Yen M. H., Chen J. Y., Chuang C. H., Namba T., Am. J. Chin. Med., 19, 265-274 (1991).

4) Yamada H., Ra K. S., Kiyohara H., Cyong J. C., Yang H. C., Otsuka Y., Phytochemistry, 27, 3163-3168 (1988).

5) Izumi S., Ohno N., Kawakita T., Nomoto K., Yadomae T., Biol. Pharm. Bull., 20, 759-764 (1997).

6) Bermejo P., Abad M. J., Diaz A. M., Fernandez L., Santos J. D., Sanchez S., Villaescusa L., Carrasco L., Irurzun A., Planta Med., 68, $106-110$ (2002).

7) Hengartner M. O., Nature (London), 407, 770_776 (2000).

8) Kikuchi S., Hiraide H., Tamakuma S., Yamamoto M., Surg. Today, 27, 226-233 (1997).

9) Salgame P., Varadhachary A. S., Primiano L. L., Fincke J. E., Muller S., Nucleic Acids Res., 25, 680-681 (1997).

10) Tarkowski E., Rosengren L., Blomstrand C., Jensen C., Ekholm S., Tarkowski A., Stroke, 30, 321-327 (1999).

11) Castaneda F., Kinne R. K., J. Cancer Res. Cin. Oncol., 127, 418-424 (2001).

12) Oh S. H., Lee B. H., Biochem. Pharmacol., 66, 725-731 (2003).

13) Yen M. H., Lin C. C., Chuang C. H., Liu S. Y., J. Ethnopharmacol., 34, 155-165 (1991).

14) Chen J. C., Chang N. W., Chung J. G., Chen K. C., Am. J. Chin. Med., 31, 363-377 (2003).

15) Wen-Sheng W., Oncogene., 22, 955-963 (2003).

16) Qian L., Murakami T., Kimura Y., Takahashi M., Okita K., Pathol. Int., 45, 207-214 (1995).

17) Bu S., Xu J., Sun J., Zhongguo Zhong Xi Yi Jie He Za Zhi, 20, 350352 (2000).

18) Zong Z., Fujikawa-Yamamoto K., Tanino M., Teraoka K., Yamagishi H., Odashima S., Biochem. Biophys. Res. Commun., 219, 480-485 (1996).

19) Smith C. A., Farrah T., Goodwin R. G., Cell, 76, 959-962 (1994).

20) Jiang S., Song M. J., Shin E. C., Lee M. O., Kim S. J., Park J. H., Hepatology, 29, 101-110 (1999).

21) Nagata S., Golstein P., Science, 267, 1449-1456 (1995).

22) Kayagaki N., Kawasaki A., Ebata T., Ohmoto H., Ikeda S., Inoue S., Yoshino K., Okumura K., Yagita H., J. Exp. Med., 182, 1777-1783 (1995).

23) Fujita T., Maruyama M., Araya J., Sassa K., Kawagishi Y., Hayashi R., Matsui S., Kashii T., Yamashita N., Sugiyama E., Kobayashi M., Am. J. Respir. Cell Mol. Biol., 27, 542-552 (2002).

24) Serrao K. L., Fortenberry J. D., Owens M. L., Harris F. L., Brown L. A., Am. J. Physiol. Lung Cell Mol. Physiol., 280, L298-L305 (2001). 